\title{
LA FORMA DE GOBIERNO EN EL CHILE ACTUAL: UN CASO DE PRESIDENCIALISMO LATINOAMERICANO EQUILIBRADO *
}

\section{The form of government in modern Chile: a case of balanced latin- american presidentialism}

Felipe Meléndez Ávila**

Universidad Mayor, Santiago de Chile

Recepción: 18/07/18. Aceptación: 11/01/19

DOI: http://dx.doi.org/10.21017/Rev.Repub.2019.v26.a58

\section{RESUMEN}

El presente trabajo aborda la forma de gobierno existente en la Constitución chilena, a la luz del presidencialismo latinoamericano, en cuanto categoría dogmática de derecho comparado. Se pretende probar que el Primer Mandatario cuenta con relevantes contrapesos en la función legislativa, dados por la existencia de leyes orgánicas constitucionales y su posterior control preventivo obligatorio por parte del Tribunal Constitucional que, en definitiva, morigeran el régimen gubernamental chileno. Para probar tal cuestión, se recurrirá al derecho comparado, a la revisión de doctrina nacional, al tiempo que se analizarán sentencias de control preventivo obligatorio de leyes orgánicas constitucionales.

Palabras clave: forma de gobierno, presidencialismo latinoamericano, Constitución chilena, pesos y contrapesos, Tribunal Constitucional.

\section{ABSTRACT}

This paper deals with the form of government existing in the Chilean Constitution, in the light of Latin American presidentialism, as a dogmatic category of comparative law. It is intended to prove that the Chief Executive has

* Artículo producto de investigación desarrollada por el autor.

** Profesor de Derecho Constitucional y director de la Escuela de Derecho, Facultad de Humanidades, Universidad Mayor, Santiago de Chile. Abogado, Licenciado en Ciencias Jurídicas y Sociales, y Doctor en Derecho, Universidad de Chile. Correo electrónico: felipe.melendez@umayor.cl. 
significant counterweights in the legislative function, given by the existence of constitutional organic laws and their subsequent mandatory preventive control by the Constitutional Court that, in short, will moderate the Chilean government regime. To prove such a question, we will resort to comparative law, to the revision of national doctrine, while we will analyze judgments of mandatory preventive control of constitutional organic laws.

Keywords: form of government, Latin American presidentialism, Chilean Constitution, checks and balances, Constitutional Court.

\section{INTRODUCCIÓN}

La doctrina chilena suele caracterizar la forma de gobierno en la Constitución actual como presidencialista, atendidas las fuertes prerrogativas con que cuenta el Primer Mandatario en el marco de la función legislativa. En tal sentido, se ha señalado que esta operaría como una desviación del modelo presidencial norteamericano. Sin embargo, esta visión no suele considerar que la estructura del poder gubernamental existente en el ordenamiento jurídico chileno se inserta dentro de un modelo propio y particular presente en los diversos países de la región, que los autores han denominado como presidencialismo latinoamericano.

Este enfoque resulta de gran relevancia para comprender en la práctica el peso real de la autoridad presidencial, por cuanto nos ofrece diversas categorías dogmáticas de derecho comparado, que permiten identificar una gradualidad e intensidad en la configuración de la forma de gobierno. Estas subcategorías se articulan en atención a los contrapesos que el Presidente debe sortear en el ejercicio de sus funciones constitucionales, principalmente, en el ámbito gubernamental y legislativo. Por nuestra parte, consideramos importante completar estas categorías, rescatando el valor de la justicia constitucional en la función legislativa, atendido el rol que los tribunales o cortes constitucionales realizan al controlar los límites trazados a los órganos del Estado.

De esta manera, a través de la forma de gobierno denominada presidencialismo latinoamericano y sus categorías, se busca comprender el sentido y alcance del régimen de gobierno existente en el Chile actual. En concreto, se pretende probar que el Primer Mandatario debe enfrentar relevantes contrapesos en la función legislativa, dados por la existencia de leyes orgánicas constitucionales y su posterior control preventivo obligatorio por parte del Tribunal Constitucional que, en definitiva, morigeran el régimen gubernamental chileno.

Para probar tal cuestión, este trabajo se dividirá en tres partes. En la primera, se revisará la forma de gobierno denominada presidencialismo latinoamerica- 
no, entendida como una categoría dogmática de derecho comparado, a fin de identificar sus fundamentos y subcategorías. En la segunda parte, se realizará un análisis de la forma de gobierno en Chile desde el punto de vista de la norma constitucional, y a la luz de las categorías anteriormente trabajadas, destacando el rol de las leyes orgánicas constitucionales y del control preventivo de constitucionalidad, como mecanismos jurídicos que morigeran el poder presidencial en la función legislativa. Finalmente, en la tercera parte, se llevará a cabo una revisión de la práctica jurisprudencial del Tribunal Constitucional, con ocasión de los mecanismos anteriormente señalados, a fin de constatar su relevancia en la morigeración de las prerrogativas presidenciales en el marco de la función legislativa.

\section{EL PRESIDENCIALISMO LATINOAMERICANO COMO CATEGORÍA DOGMÁTICA DE DERECHO COMPARADO}

La doctrina comparada suele identificar dos principales regímenes de gobierno en el marco de la forma de Estado democrática, a saber, el presidencial y el parlamentario, los cuales son sus tipos ideales, a la usanza weberiana, Estados Unidos e Inglaterra, respectivamente (Pasquino, 2011, pp. 248-258). En tal sentido, aquellos sistemas que se alejan de esta categoría adoptan formas más cercanas a los regímenes autocráticos. Tal sería el caso del presidencialismo latinoamericano, el cual se caracterizaría, precisamente, por acercarse a formas de gobierno ajenas a la democracia, operando, la mayoría de las veces, como una categoría peyorativa destinada a caracterizar la forma de distribución del poder en las constituciones de América Central y del Sur.

Sin embargo, tal como ha destacado Gargarella (2015, p. 8), es posible «tomar en serio el constitucionalismo de la región», atendida la tradición compartida, en torno, precisamente, a la configuración del poder presidencial. Al respecto, un sector de la doctrina ha mirado con mayor detalle la configuración de los regímenes latinoamericanos, ofreciendo una visión más precisa y certera de la operativización de la forma de gobierno. En efecto, se ha destacado como uno de sus rasgos característicos la intervención del Ejecutivo en el proceso legislativo, lo que acontece en al menos tres actos: «iniciativa de ley, la facultad de veto y la promulgación y publicación de la ley» (Orozco y Zovatto, 2009, p. 67), aspectos que darían cuenta de la existencia de una tradición compartida (Nohlen, 2011, pp. 87-111), lo que incluso ha sido denominado como constitutivo de un ius constitutionale commune latinoamericano (Valadés, 2014, p. 187).

A este respecto, resulta fundamental la inicial obra de Loewenstein, quien tempranamente destaca la presencia de una categoría autónoma, independiente de la existente en Estados Unidos: el presidencialismo latinoamericano. En 
efecto, para el autor, existen tres categorías de regímenes presidenciales, a saber, el presidencialismo puro, el atenuado y el parlamentarismo aproximado (Loewenstein, 1949, pp. 22-23). Estas tres categorías se articulan con base en el grado de autonomía que tiene el Primer Mandatario en la dirección de la función ejecutiva, ya sea por el nivel de influencia del gabinete ministerial, como por el contrapeso que puede llegar a tener con el Congreso Nacional, una suerte de control interorgánico.

Para el autor, estas categorías de presidencialismo latinoamericano se distanciarían de lo que este denomina «neopresidencialismo», esto es, «aquella forma de Gobierno, bajo la cual, a través de especiales combinaciones constitucionales con los órganos constituidos, el poder político del Presidente-Ejecutivo es superior al de todos los demás órganos del Estado». En efecto, se trata de un gobierno que en esencia es autoritario, entendido como aquel gobierno «en el cual el pueblo, mediante el ejercicio de un sufragio razonablemente amplio y en elecciones no amañadas, no participa en la formación de la voluntad del Estado. Su técnica consiste en la concentración de las funciones ejecutiva y legislativa en manos del Ejecutivo» (Loewenstein, 1949, p. 55).

Posteriormente, otros autores han retomado la senda trazada por Loewenstein, pero desde distintas perspectivas de análisis. Entre nosotros, se destacan las categorías propuestas por Nogueira, quien distingue entre regímenes autoritarios con fórmulas presidencialistas y formas de gobierno de presidencialismo democrático. Respecto de estas últimas, identifica dos tipos, a saber, el presidencialismo puro y el atenuado o con rasgos parlamentarios (Nogueira, 2015, p. 423). El autor determina la existencia de estas dos categorías, en atención a la existencia o no de instituciones o mecanismos jurídicos en los textos constitucionales que terminen afectando la autonomía del Primer Mandatario en el manejo de la función legislativa.

Dentro de los promotores del presidencialismo latinoamericano también destaca el trabajo desarrollado a nivel comparado por Carpizo, quien da un paso más allá en la comprensión de esta forma de gobierno. En efecto, sostiene que la comprensión de este fenómeno debe realizarse tanto desde la perspectiva de la norma constitucional, como de la realidad político-constitucional, de forma de poder apreciar la interacción que resulte de ambos elementos. De esta manera, desde la perspectiva de la norma constitucional, el autor distingue cinco tipos de presidencialismo latinoamericano, a saber, presidencialismo puro, predominante, atemperado, con matices parlamentarios y parlamentarizado. El hilo conductor de estas categorías está dado por el grado de autonomía del Presidente de la República en atención a la existencia de diversos contrapesos institucionales establecidos en los textos constitucionales. Por su parte, desde la perspectiva de la realidad constitucional, identifica tres tipos, conformados 
por el presidencialismo hegemónico, el equilibrado y el débil (Carpizo, 2007, pp. 197-212), donde el foco está centrado en la relación del Presidente con los partidos políticos y su presencia en el Congreso.

De esta forma, el presidencialismo latinoamericano, en cuanto categoría dogmática de derecho comparado, tiene rasgos propios que justifican su utilización autónoma respecto de las demás formas de gobierno elaboradas por la dogmática jurídica y la ciencia política. Por su parte, que de la revisión de las diversas categorías elaboradas por los autores, puede apreciarse que las variaciones en esta forma de gobierno están dadas tanto por los contrapesos normativos, como prácticos, que pueden realizar otros órganos constitucionales en prerrogativas propias del Primer Mandatario. Dependiendo de su grado de preponderancia, estos pueden potenciar, equilibrar o morigerar o bien, minimizar el poder presidencial, particularmente, en el ámbito de la función legislativa.

Con todo, resulta necesario complementar las categorías precedentes, ya que como sostiene Ackerman, la división de poderes no solo acontece entre el Presidente y el Congreso, siendo necesario añadir, entre otros, «el estatus constitucional de los tribunales» (Ackerman, 2007, p. 18). En efecto, a partir de la segunda mitad del siglo XX, comienza paulatinamente a arraigarse la justicia constitucional a nivel europeo (Cappelletti, 1980, pp. 76-78), proceso que llegará a América Latina a fines de dicha centuria (Landa, 2017, p. 8), modificando el rol de los textos constitucionales. Ello debido a que estos pasan de ser normas políticas y programáticas a ser concebidos como normas jurídicas propiamente tales. Ya sea a través del establecimiento de modelos semejantes a la judicial review norteamericana o bien, a la instauración del modelo europeocontinental de raigambre kelseniana, de Tribunales o Cortes Constitucionales (García Belaunde, 2004, pp. 312-317).

De ahí que, manteniendo el criterio articulado en torno a los contrapesos presidenciales en el marco de la función legislativa, resulta necesario añadir otro actor que también participa de ella, a saber, el Tribunal Constitucional (TC). Ello por cuanto, a través del control de constitucionalidad de la legislación, a este le corresponde oficiar como legislador en sentido negativo (Kelsen, 1999, pp. 36-37), al tener la prerrogativa de derogar -abrogar- una norma de rango legal con efectos erga omnes.

De esta manera, la introducción del control de constitucionalidad de la legislación entregado a un Tribunal o Corte Constitucional introduce un nuevo elemento a considerar para los efectos de las relaciones interorgánicas en el ámbito de la función legislativa, más aún si se tiene en cuenta que el presidencialismo latinoamericano -en cuanto categoría dogmática de derecho comparado- atri- 
buye importantes prerrogativas legislativas al Primer Mandatario, situándolo como el principal órgano colegislador. Por tanto, la revisión del grado de intensidad de los poderes presidenciales hace imprescindible considerar el papel del Tribunal o Corte Constitucional, en cuanto mecanismo de contrapeso del Presidente de la República con ocasión de la función legislativa, como veremos más adelante.

\section{EL RÉGIMEN DE GOBIERNO EN CHILE DESDE LA NORMA CONSTITUCIONAL}

La forma de gobierno no suele estar expresamente señalada en una disposición constitucional, por lo que su identificación se realiza a partir del cotejo de las atribuciones y prerrogativas de los órganos públicos con categorías dogmáticas de derecho comparado. La Constitución chilena no escapa de esta realidad, ya que si bien hay una opción expresa en cuanto a la forma de Estado democrática (Art. 4), nada dice respecto del sentido del régimen de gobierno.

La doctrina nacional, mayoritariamente, sostiene que el régimen de gobierno en Chile es presidencialista, guardando importantes diferencias con el existente en la Constitución de los Estados Unidos. Para afirmar ello, los autores se centran en las fuertes prerrogativas con que cuenta el Presidente de la República respecto de los demás poderes públicos, especialmente en la función legislativa, las cuales le otorgan un claro carácter de colegislador.

En efecto, la forma de gobierno contemplada en la Constitución chilena tiene rasgos propios y distintivos que la alejan de su símil norteamericano. En primer término, porque el Primer Mandatario tiene iniciativa legislativa (mensajes), e incluso se le reservan materias a su iniciativa exclusiva (Art. 65). La más importante de ellas es la ley de presupuestos, frente a la cual el Congreso tiene atribuciones bastante acotadas, toda vez que este no podrá aumentar ni disminuir la estimación de los ingresos, al tiempo que se le entrega solamente la facultad de disminuir los gastos previstos en este proyecto de ley, negándole, de esta forma, la posibilidad de aumentarlos o rechazarlos, así como también la posibilidad de crear gastos nuevos (Art. 67). En segundo lugar, le asiste la facultad de solicitar al Congreso la autorización para dictar disposiciones con fuerza de ley a través de decretos supremos, previa ley delegatoria (Art. 64). En tercer lugar, este tiene la posibilidad de presentar urgencias durante el proceso de discusión legislativa, obligando al Congreso a tener que pronunciarse dentro de plazos acotados respecto de los proyectos de ley incluidos en la referida declaración (Art. 74). En cuarto lugar, a los Ministros de Estado se les entrega la prerrogativa de poder asistir a las sesiones de la Cámara de Diputados o del Senado, tomar parte del 
debate legislativo, e incluso con derecho preferente en el uso de la palabra, aunque sin derecho a voto (Art. 37 inc. 1). En quinto lugar, cuenta con la atribución de sancionar o vetar un proyecto de ley aprobado por el Congreso Nacional. En el evento que opte por esta última alternativa, este tendrá un carácter suspensivo, pudiendo ser realizado en términos totales o parciales, generándosele la posibilidad al Primer Mandatario de formular observaciones aditivas, sustitutivas o supresivas. Frente a ellas, las Cámaras solo pueden revertirlas, insistiendo en su proyecto inicial con el voto favorable de las dos terceras partes de los miembros presentes (Art. 73).

Sin embargo, consideramos que la forma de gobierno en Chile no solo se caracteriza por ser distinta al presidencialismo norteamericano, sino que, al mismo tiempo, tiene rasgos compartidos con el denominado presidencialismo latinoamericano. Ello, atendidas las fuertes asimetrías existentes entre el Primer Mandatario y el Congreso Nacional, en el marco de la función legislativa, lo que justifica la utilización de esta categoría dogmática de derecho comparado.

Este enfoque no solo sirve para situar nuestra forma de gobierno en el concierto latinoamericano, sino que también posibilita la utilización de estas categorías, ofreciendo un modo distinto de compresión del poder presidencial en Chile. Esta mirada cobra particular importancia si se considera que la doctrina nacional mayoritaria califica nuestro régimen de gobierno como presidencialista $^{1}$, ultrapresidencial (Godoy, 2003, p. 12), hiperpresidencialista (RuizTagle, 2014, p. 159) e incluso como neopresidencial (Ruiz-Tagle, 2006, p. 210), esta última forma propia de los estados autocráticos. Y que a partir de tales caracterizaciones, se han promovido diversas propuestas de reforma que van desde una racionalización (Molina, 1997, pp. 98-103) o flexibilización del presidencialismo (Ruiz-Tagle, 2016, p. 192), la adopción de una forma semipresidencial (Nogueira, 2008, pp. 503-525), hasta la instauración de un régimen parlamentario (Valenzuela, 1985, pp. 46-69).

En efecto, existen distintas formas de analizar las relaciones interorgánicos existentes en la Constitución actual, a la luz del presidencialismo latinoamericano, dado por el grado de independencia del Primer Mandatario respecto del Congreso Nacional. Por tal motivo, en este trabajo se optará por observar el régimen de gobierno chileno desde una interacción mayor, toda vez que se buscará precisar la participación del Tribunal Constitucional en la instancia donde participan los distintos poderes públicos: el proceso de formación de las leyes.

1 Verdugo et al., 1999, p. 8; Molina, 2006, pp. 306-310; Cruz-Coke, 2009, p. 189; Fermandois y García, 1999, p. 282; Ríos, 2013, p. 149. 


\subsection{Mecanismos jurídicos que morigeran el poder presidencial en la función legislativa}

Las reformas constitucionales de 2005 marcaron un hito relevante en la Constitución chilena, por cuanto lograron dejar atrás -en términos relevantes- los vestigios autoritarios provenientes del régimen militar, que otorgaban un verdadero rol tutelar a las Fuerzas Armadas respecto de la institucionalidad toda. Con ello se posibilitó la subordinación de esta al poder civil.

Asimismo, a partir de 2005 estamos en presencia de un texto con poderes presidenciales más morigerados, ya que los cambios publicados dicho año, tal como destaca Navarro, revierten «una tendencia que fue predominante en Chile, particularmente en el siglo XX, y es que se busca una reducción de las potestades del Presidente de la República, de modo que exista un mayor equilibrio de poderes con el Congreso Nacional». En ellos destaca la constitucionalización de las comisiones investigadoras de la Cámara de Diputados, la introducción de la interpelación parlamentaria a los ministros de Estado -aunque sin la posibilidad de voto de desconfianza o censura-, y la reducción del periodo presidencial, de 6 a 4 años (Navarro, 2014, p. 17).

De igual manera, se modifica fuertemente la composición y forma de nominación del Tribunal Constitucional, dejando de participar en su designación las Fuerzas Armadas a través del Consejo de Seguridad Nacional, para quedar en manos de los órganos constitucionales: Presidente de la República, Congreso Nacional y Poder Judicial. Por su parte, se aumentan en términos relevantes sus prerrogativas, a través de la incorporación de la acción de inaplicabilidad y de la creación de la acción de inconstitucionalidad, prerrogativa inédita en la historia constitucional chilena (Gómez, 2005, p. 652). Con ello, el TC logra autonomía, lo cual permite reafirmar el carácter normativo de la Constitución chilena.

Sin embargo, pese a estas importantes enmiendas introducidas en la Constitución chilena tras las reformas de 2005, subsisten en la actualidad mecanismos jurídicos cuyo origen se remonta al texto promulgado por el régimen militar, y que tornan particularmente relevante la participación del Tribunal Constitucional en el proceso de formación de las leyes, a saber, el control preventivo obligatorio de las leyes orgánicas constitucionales (LOC), estas últimas dotadas de un quorum de carácter supramayoritario.

Las LOC como normas con quorum supramayoritario y su control preventivo por el Tribunal Constitucional

Las leyes orgánicas constitucionales requieren para su creación, modificación y derogación, del voto favorable de las cuatro séptimas partes de los diputados 
y senadores en ejercicio, respectivamente (Art. 66). La centralidad de este tipo de normas de rango legal no solo se encuentra en el quorum sino que también en su alcance y ámbito de aplicación. Ello debido a que las LOC, por mandato constitucional, abarcan una gran cantidad de materias, regulando la casi totalidad de los órganos constitucionales, como también algunos derechos fundamentales. $^{2}$

Al respecto, la doctrina ha identificado dos dificultades respecto de ellas. Por un lado, una suerte de constitucionalización de estas normas de jerarquía legal, al tener quórum de creación, modificación y derogación propios de normas de rango constitucional. En efecto, para Huneeus la razón de ser de este mecanismo en la Constitución chilena «no se encuentra en la rigidez de las Constituciones para proteger los derechos de la minoría, pues su objetivo fue distinto: asegurar la continuidad del orden institucional impuesto por un régimen militar. Lo que establece es una tiranía de la minoría, no su defensa» (Huneeus, 2012, p. 39). En un sentido similar, Zapata sostiene que las LOC, desde un punto de vista político, son una manifestación del constituyente de 1980 destinado a «limitar la capacidad reguladora de la ley», principalmente, respecto del legislador común. En tal sentido, sostiene el autor, las LOC pese a tener jerarquía de norma de rango legal, son expresión del constituyente de querer constitucionalizar diversas áreas del dominio legal. De esta manera, ellas terminan por limitar «el esfuerzo reformista de las mayorías simples» (Zapata, 2016, pp. 401-402).

Y por otro, la segunda dificultad que ha identificado la doctrina en las LOC, es que estas otorgan un rol preponderante a las minorías políticas, las cuales quedan dotadas con un verdadero poder de veto. Al respecto, Sierra sostiene que la existencia del quórum supramayoritario es propia del poder constituyente, y no del legislativo, lo que transforma a este mecanismo en una «anomalía democrática», ya que «exigir más de la mitad más uno implica dar a la minoría, respecto de la legislación, un poder de veto análogo al que ejercen respecto de la Constitución» (Sierra, 2011, pp. 14-16). Zapata, por su parte, argumenta que la existencia de estos quórum ha terminado en la práctica «subsidiando de manera excesiva a las fuerzas políticas que pierden las elecciones» (Zapata, 2016, p. 403). Este diseño pone en jaque los poderes presidenciales, toda vez que permite a las minorías políticas alojadas en las Cámaras del Congreso Nacional operar como jugadores con poder de veto cuando se legisle sobre este tipo de normas de rango legal (Tsebelis, 2006, pp. 103-108).

2 En efecto, la Constitución dispuso que 17 materias debían ser reguladas por las LOC. Al respecto, véase Zapata, 2016, p. 407. 
Sin embargo, esta configuración ha tenido particular efecto en los equilibrios institucionales, ya que, como señala Boeninger, la existencia de leyes con quórum supramayoritario haría que la práctica de la forma de gobierno se asimile a los regímenes parlamentarios, ya que «el Presidente, así como el Primer Ministro en su caso, tiene que trabajar en estrecha relación con su coalición en el Parlamento, así como mantener vínculos con la "oposición de su majestad"». Añade que este esquema partidista en el interior del Congreso Nacional ha obligado al Presidente «a procurar mantener un clima de relaciones constructivas, disposición al diálogo y al acuerdo con los partidos de oposición, cuyos votos resultan indispensables para aprobar leyes de quórum especial o para suplir cualquier ausencia o desafección en las filas oficialistas» (Boeninger, 2008, p. 195). Esta conducta es propia de aquellos sistemas partidistas donde no hay una mayoría hegemónica para el Primer Mandatario, lo que en la práctica termina mitigando los poderes presidenciales, ya que «si el Presidente no actúa con una visión más pluralista en el proceso de toma de decisiones, pone en peligro a la coalición que le sostiene» (Nolte, 2003, p. 54).

De esta forma, se produce un efecto sumamente paradojal con ocasión de las LOC. Efectivamente, ellas dan cuenta de una desconfianza hacia las mayorías políticas, representadas en el seno del Congreso, otorgando este denominado «poder de veto» a las minorías políticas. Más aún cuando buena parte de dichas normas fueron dictadas por el régimen militar, previo al restablecimiento de los colegisladores democráticos Presidente de la República-Congreso Nacional, en marzo de 1990 (Atria, 2014, pp. 61-62). Sin embargo, este mecanismo ha obligado al Primer Mandatario a tener un enfoque más dialogante en el proceso de formación de las leyes. Ello debido que pese a que cuenta con iniciativa legal y en algunas materias iniciativa exclusiva, urgencia legislativa, participación en el proceso de discusión legislativa, poder de veto suspensivo, entre otras prerrogativas, el Primer Mandatario no puede sacar adelante la legislación que aborde temas de LOC, si es que no cuenta con las supramayorías necesarias para obtener su aprobación. En tal sentido, todas las prerrogativas anteriormente señaladas pierden total eficacia.

Las LOC no solo cuentan con un quórum supramayoritario, sino que además son objeto de control preventivo obligatorio por parte del Tribunal Constitucional. Este mecanismo opera en los siguiente términos: una vez que un determinado proyecto de ley materia de LOC ha sido aprobado por ambas Cámaras del Congreso Nacional, debe ser remitido por este al TC, previo a su promulgación por parte del Presidente de la República, a fin de que se realice un control a priori y abstracto sobre él. En el evento que sobre el proyecto se dicte una sentencia estimatoria de inconstitucionalidad, este no podrá convertirse en ley, pese a que haya sido aprobado con un quórum supramayoritario por el Congreso Nacional. Por su parte, en el caso que se dicte una sentencia 
de estimación parcial, solo podrá convertirse en ley aquella parte del proyecto que haya sido declarada constitucional, sin posibilidad de reenvío, esto es, sin que las Cámaras tengan la posibilidad de salvar el vacío normativo (Bon, 1998, p. 166). Finalmente, solo en el caso que se dicte una sentencia desestimatoria el proyecto podrá pasar a la promulgación presidencial, de forma que sea publicado y entre en vigor.

El control preventivo es una institución excepcionalísima a nivel comparado, ya que el modelo europeo-continental de justicia constitucional creado por Kelsen y expandido tras la segunda posguerra se caracteriza por contemplar la modalidad represiva, sucesiva, o a posteriori; vale decir, solo se aboca a leyes vigentes, que se encuentra en vigor (Cappelletti, 1966, pp. 34-48). En tal sentido, el control preventivo, en cuanto diseño normativo, ha respondido más bien a finalidades propias y específicas de los textos sobre los cuales se ha articulado. En el caso francés, la finalidad fue crear una instancia destinada a establecer una fuerte limitación al parlamento, de manera de reformar la autoridad presidencial en materia legislativa (Pardo, 1990, p. 36). En Chile, en cambio, el diseño del control preventivo obligatorio no fue tanto la defensa del Primer Mandatario frente al Congreso sino, más bien, el temor al desborde gubernamental de los lineamientos establecidos por la Carta de 1980, de forma de evitar la existencia de un Presidente que pretenda cambiar el estatus quo, valiéndose de disposiciones constitucionales, tal como lo habría llevado a cabo Salvador Allende durante el gobierno de la Unidad Popular (Meléndez, 2017).

De esta manera, el quórum supramayoritario de las LOC y su posterior control preventivo obligatorio por parte del TC son dos mecanismos que pueden limitar en términos relevantes el manejo y control de la función legislativa por parte del Primer Mandatario. Sin embargo, al hacerlo, se genera una paradoja, por cuanto al restringir estas prerrogativas, al mismo tiempo puede favorecer el régimen democrático de gobierno, al equilibrar las fuertes atribuciones con que cuenta el Ejecutivo en el proceso de formación de las leyes. La práctica jurisprudencial da varias señales al respecto, como se verá a continuación.

\section{EL RÉGIMEN DE GOBIERNO EN CHILE DESDE LA PRÁCTICA JURISPRUDENCIAL}

La revisión de la práctica jurisprudencial del control preventivo de leyes orgánicas constitucionales da luces respecto del rol que el Tribunal Constitucional ha desempeñado en la función legislativa y, a través de ella, en la configuración de la forma de gobierno en la Constitución chilena. Al respecto, se identifican dos aspectos que morigeran en términos relevantes las prerrogativas presidenciales en el proceso de formación de las leyes, que nos 
permiten dar cuenta del presidencialismo latinoamericano equilibrado existente en la Carta actual. Por un lado, el efecto expansivo otorgado a las LOC $\mathrm{y}$, por otro, la intervención en prerrogativas presidenciales, en casos de decisiones atípicas.

\subsection{El efecto expansivo de las LOC}

Desde el punto de vista práctico, el Tribunal Constitucional ha tendido a ampliar el alcance de las LOC, yendo más allá de los casos previstos por la Constitución para este tipo de normas. En ello ha influido de forma determinante la existencia de leyes mixtas, vale decir, normas que contienen en un mismo texto autoritativo tanto disposiciones de ley ordinaria como de LOC, lo que ha abierto el problema de quién debe calificar las normas objeto de este control, el Congreso o el Tribunal Constitucional. Respecto de ellas, el TC ha creado criterios para justificar la ampliación del control preventivo de constitucionalidad; en particular, el denominado «contenido imprescindible-complemento indispensable» (Sierra, 2011, p. 36).

En efecto, producto de la existencia de leyes mixtas se ha generado el fenómeno conocido como el «desmembramiento de las LOC»; vale decir, proyectos de ley que además de regular materias de ley orgánica constitucional contienen materias de ley ordinaria en un mismo cuerpo normativo (Sierra, 2011, p. 43). Este fenómeno trae aparejado un problema central, toda vez que la Constitución no señalaría expresamente cuál es el órgano encargado de calificar las normas que deben ser objeto de control preventivo obligatorio y las que no. Frente a ello existen al menos dos soluciones hermenéuticas, a saber, que esta quede radicada bien en el Congreso Nacional, o bien en el Tribunal Constitucional (Zapata, 2016, p. 441).

Se ha planteado que si se optara por la primera opción, eventualmente una mayoría parlamentaria podría tratar de eludir dicho control al calificar como ley ordinaria una LOC, evitando así el control de constitucionalidad. En cambio, si se opta por radicar la calificación en el Tribunal Constitucional, este podría invadir la órbita de atribuciones del propio legislador. Los autores coinciden en que la calificación debe ser realizada, preferentemente, por el TC, ya que, de esta manera, sería posible hacer efectivo, por una parte, el principio de supremacía constitucional (Zapata, 2016, pp. 435-441), y por otra, el carácter normativo de la Constitución (Bordalí, 2005, p. 241). El problema práctico radica en que el TC se ha caracterizado por una actitud más activa, ampliando la calificación realizada por el Congreso Nacional (Zapata, 2016, pp. 433-448). En la adopción de dicha actitud han tenido particular relevancia los criterios jurisprudenciales creados por el Tribunal Constitucional para fundamentar su interpretación. 
$\mathrm{El}$ «contenido imprescindible-complemento indispensable» se ha constituido en el criterio jurisprudencial creado por el TC chileno para poder ampliar el alcance de las materias que deben ser reguladas por mandato de la Carta Fundamental, a través de una ley orgánica constitucional, pese a no estar contemplado expresamente. Un sector de la doctrina considera que en ciertos casos es razonable su utilización, atendido los diversos tipos de LOC previstos por la Constitución (Zapata, 2016, pp. 408-411). Otro sector, en cambio, reniega la existencia de este criterio, ya que adolecería de un «subjetivismo confuso», pues dejaría en manos del intérprete determinar cuál sería el «contenido imprescindible» como el «complemento indispensable», afectando, con ello, la seguridad jurídica del control preventivo (Mohor y Varas, 1986, pp. 260-261). Asimismo, porque su utilización con efectos expansivos aumentaría la anomalía democrática de este tipo de leyes con quórum supramayoritario (Sierra, 2011, pp. 59-63).

Ahora bien, más allá de las dificultades hermenéuticas producidas por las múltiples materias de LOC contempladas por la Constitución, los autores han resaltado una serie de casos en los cuales el TC, a través del criterio jurisprudencial «complemento indispensable», ampliaría más allá de lo razonable el ámbito material de las LOC. Emblemáticos resultan ser los múltiples casos de «plantas de personal», toda vez que la Constitución de 1980 dispone expresamente solo en dos ocasiones cuándo esta materia debe ser objeto de una ley orgánica constitucional (Fuerzas Armadas y Carabineros, y Tribunal Constitucional $)^{3}$, debiendo, por tanto, recurrirse a una ley ordinaria en el resto de los casos. Sin embargo, en varias ocasiones el TC ha ampliado su control en este ámbito a otros órganos constitucionales, sin estar facultado de forma expresa para ello (Sierra, 2011, p. 58).

De esta manera, se produce un efecto paradojal de esta prerrogativa. Ello por cuanto el control preventivo obligatorio está establecido en íntima relación con las leyes orgánicas constitucionales, las que atendido su quórum supramayoritario miran con desconfianza a las mayorías políticas, dando un poder más allá de lo razonable a las minorías, las que se configuran con un verdadero poder de veto. A ello se adiciona la conducta práctica del TC, el cual, paulatinamente, ha tendido a ampliar las materias que comprenden dicho tipo de normas. Pero, por otro lado, al proceder de esta manera, el Tribunal Constitucional ha terminado relativizando las fuertes prerrogativas presidenciales en materia legislativa, generando la paradoja de que, como un instrumento temeroso de las mayorías en cuanto expresión de la democracia en cuanto forma de gobierno -el quorum supramayoritario de las LOC-, ha permitido

3 CPR, Arts. 105, y 92 inciso 6. 
relativizar las fuertes prerrogativas presidenciales en materia legislativa, y con ello, configurar en Chile un régimen presidencial latinoamericano de carácter equilibrado.

\subsection{El caso de las decisiones atípicas}

Otra forma en que ha sido posible constatar una morigeración del poder presidencial, se aprecia en diversas sentencias dictadas por el Tribunal Constitucional en el marco del control preventivo obligatorio de constitucionalidad de proyectos de LOC. En tal sentido, destacan aquellas que la doctrina denomina «interpretativas» (Díaz Revorio, 2001), «atípicas» (Nogueira, 2004) o «intermedias» (Bazán, 2015); esto es, decisiones que no se limitan a pronunciarse simplemente acerca de la constitucionalidad o inconstitucionalidad de un determinado texto normativo, sino que van más allá. A partir de la distinción entre enunciando normativo y norma, el TC establece diversos sentidos posibles a partir de un mismo texto, el cual queda inalterado (Guastini, 2017, pp. 77-79).

En el caso del TC chileno, es posible apreciar esta práctica jurisprudencial, la cual remonta sus orígenes a la década de los 80 (Valenzuela, 2006, pp. 35-41) -en pleno régimen militar- y cuyo ejercicio se ha consolidado durante el periodo democrático tal como da cuenta la doctrina nacional. ${ }^{4} \mathrm{~A}$ través de este tipo de decisiones, el TC ha hecho llamados al legislador para proceder de determinada manera (exhortativas), limitado el sentido y alcance de las disposiciones normativas (restrictivas) e, incluso, modificado derechamente el enunciado normativo mismo de un proyecto de ley orgánica constitucional, oficiando como un verdadero legislador positivo (sustitutivas). Como veremos a continuación, con ocasión de estas prácticas, el TC ha intervenido en prerrogativas propias del Primer Mandatario, pasando a jugar un relevante papel de contrapeso de este, con ocasión de la función legislativa.

$\mathrm{Al}$ respecto, destaca dentro de aquellas decisiones exhortativas que enfrentan al poder presidencial, el caso «CONAF» por medio del cual el TC hizo un llamado directo al Primer Mandatario. El problema jurídico giró en torno a la constitucionalidad de la relación entre la naturaleza jurídica de esta corporación de derecho privado y las funciones públicas que le eran encomendadas por ley. En particular, producto de que la Ley nro. 18.348 que lo rige, pese a haber sido promulgada en 1984, no se encontraba vigente al no haberse dictado, por parte del Primer Mandatario, el decreto supremo que ordenaba la disolución de las Corporaciones que le sucedieron, de eminente carácter privado,

$4 \mathrm{Al}$ respecto, véase: Nogueira, 2004; y Zapata, 2006. 
aspecto que fue objeto de una importante controversia en el interior del propio Tribunal Constitucional.

El voto de mayoría decidió declarar constitucional el proyecto de ley que otorgaba nuevas facultades públicas a CONAF, pese a cuestionar su naturaleza jurídica. Para fundamentar tal posición sostuvo que la inconstitucionalidad solo debe operar cuando «no existe ninguna interpretación posible que permita declarar su conformidad con la Constitución». En el caso en cuestión, sin embargo, no habría operado este criterio, toda vez que no queda clara aquella interpretación más favorable. Por el contrario, el propio TC sostuvo que se «debe evitar que la declaración de inconstitucionalidad produzca efectos que puedan resultar aún más inconstitucionales (Rol 616)»..$^{5}$ Es por ello que, en definitiva, decidió «hacer presente a los Poderes Colegisladores la inconveniencia de la mantención de situaciones constitucionalmente anómalas como las aludidas». Pero a su vez, procedió a exhortar «a S. E. la Presidenta de la República para que regularice la naturaleza jurídica de CONAF, procediendo a la dictación del Decreto Supremo a que se refiere el artículo 19 de la Ley nro. 18.348, publicada en 1984, o empleando otro medio constitucionalmente idóneo que el Gobierno estime adecuado». ${ }^{6}$ El voto de minoría, por su parte, estuvo de acuerdo en el cuestionamiento de la función desempeñada por CONAF, como las medidas que debían practicarse por parte de los órganos colegisladores, prácticamente por los mismos argumentos que la mayoría; pero, en vez de exhortar, estuvo por decretar derechamente la inconstitucionalidad del referido proyecto de ley. ${ }^{7}$

Por su parte, dentro de aquellas decisiones atípicas de carácter restrictivo, destacan dos casos que se pronuncian sobre el alcance de la potestad reglamentaria presidencial. En el primero de ellos -Probidad Administrativa- se controlaba el proyecto de ley que entregaba al reglamento el establecimiento de «los requisitos de las declaraciones de intereses», como también de «las demás normas necesarias para dar cumplimiento a las disposiciones de este párrafo». Frente a esta delegación realizada por el legislador hacia la potestad reglamentaria presidencial, el Tribunal Constitucional decidió declararlo constitucional pero «en el entendido de que el reglamento a que se alude solo ha de contemplar los requisitos de forma de la declaración de intereses o de su actualización». En cambio, estimó prohibir la posibilidad de que se ampliaran requisitos de contenido, ya que según dispuso, estos «se encuentran determinados por los artículos 60 y 61, antes mencionados».8

5 STC Rol nro. 1024-2008, considerando 22. .

6 STC Rol nro. 1024-2008, resolutiva 5. .

7 STC Rol nro. $1024-2008$, voto de minoría $5 .^{\circ}, 6 .^{\circ}, 9 .^{\circ}, 10 .^{\circ}$ y $15 .^{\circ}$.

8 STC Rol nro. 299-1999, considerando 9.. 
En el segundo de ellos -Modificación de LOC Contraloría- esta actitud menos favorable hacia la potestad reglamentaria presidencial queda más patente. En efecto, en este caso, al Tribunal Constitucional le correspondió pronunciarse, entre otros enunciados normativos, acerca de aquel que introducía cambios al régimen de toma de razón -control de legalidad de los actos de la administración de carácter preventivo- practicado por la Contraloría General de la República, ampliando la facultad del Presidente de insistencia en su decreto inicial, pese a la representación formulada por el órgano contralor. A juicio del Tribunal, esta disposición era de tal amplitud que podía permitir que el Primer Mandatario insistiese en su decreto pese a haber sido representado por el Contralor como inconstitucional. De esta manera, el TC dictaminó que la referida disposición era constitucional «en el claro entendido que la insistencia del Jefe de Estado es improcedente en el caso que los decretos o resoluciones hayan sido representados por el Contralor por ser contrarios a la Constitución». ${ }^{9}$ El voto de minoría, por su parte, fue más allá por cuanto estuvo por decretar la inconstitucionalidad del referido enunciado normativo, debido a la «evidente contradicción con el artículo 88 de la Carta Política, pues mantiene la posibilidad de la insistencia en el caso de los decretos supremos y de la resolución de los Jefes de Servicios que sean inconstitucionales, facultad que prohíbe expresamente la Constitución actual». ${ }^{10}$

Finalmente, dentro de aquellas decisiones atípicas de carácter sustitutivo, destaca el caso «Modificación del Código Orgánico de Tribunales», proyecto de ley que introduce -entre otras enmiendas legislativas- el cargo de «abogado asistente del Fiscal», aspecto sobre el cual el TC tuvo una importante controversia. En efecto, el problema de este nuevo cargo radicaba en que el proyecto de ley lo homologaba a la calidad de fiscal para ciertas actuaciones del proceso penal, aunque sin señalar expresamente su carácter dentro de la estructura organizacional del Ministerio Público. En tal sentido, el fallo de mayoría, recurriendo al principio «uniforme y reiteradamente aplicado por esta Magistratura, consistente en buscar la interpretación de las normas que permita resolver, dentro de lo posible, su conformidad con la Carta Fundamental», sostuvo que el referido enunciado normativo «es constitucional en el entendido que "el abogado asistente del fiscal" a que se refiere la norma, debe haber sido designado o contratado como funcionario del Ministerio Público y que no podrá realizar ante los tribunales de justicia otras gestiones o actuaciones que las expresamente establecidas por la ley». ${ }^{11}$

9 STC Rol nro. 356-2002, considerando 9.․

10 STC Rol nro. 356-2002, voto de minoría $12 .^{\circ}$, pronunciado por la ministra, Sra. Bulnes.

11 STC Rol nro. 458-2005, considerando $15 .^{\circ}$. 
El voto de minoría, en cambio, estuvo por declararlo inconstitucional, atendida las falencias normativas que traía aparejada su aprobación -vía decisión sustitutiva- de este nuevo cargo, particularmente, en lo que dice relación con la ausencia de una homologación de funciones expresa entre el fiscal y su abogado asistente, como también, debido a la «ausencia de un estatuto propio que determine la forma de su nombramiento, sus atribuciones ni la responsabilidad que les asiste en el ejercicio de sus funciones, como sí ocurre con los fiscales que por mandato de la Constitución actúan como Ministerio Público». ${ }^{12}$

De esta manera, en este caso, el Tribunal Constitucional declaró tácitamente inconstitucional el enunciado normativo aprobado por los órganos constitucionales, pero, al mismo tiempo, estableció una serie de obligaciones, no previstas en el proyecto de ley, ni mucho menos por la Constitución, conformando, de esta manera, una verdadera decisión sustitutiva. Desde el punto de vista competencial, el Tribunal intervino en lo decidido por los órganos colegisladores, pero además, en facultades privativas del Presidente de la República, en el marco del actual régimen presidencialista previsto por la Constitución chilena, que dispone que la creación de nuevos empleos rentados, determinar funciones y atribuciones es materia de iniciativa exclusiva del Primer Mandatario (Art. 65, inc. 4, nro. 2).

En síntesis, las diversas decisiones atípicas analizadas muestran el importante rol de contrapeso que desempeña el Tribunal Constitucional, a través del control preventivo obligatorio de leyes orgánicas constitucionales. Ello no solo porque limita la actividad del Primer Mandatario en su calidad de órgano colegislador, sino también debido a que afecta prerrogativas propias del ejecutivo, como la potestad reglamentaria -exhortativas y restrictivas-, así como también en materias de gasto -sustitutivas-, que en el marco de nuestra Carta Fundamental, representan una de las principales materias de iniciativa exclusiva del Presidente de la República. De ahí que es que a través de la revisión práctica de decisiones atípicas, es posible apreciar la morigeración de las atribuciones presidenciales, constituyendo al régimen chileno como un presidencialismo latinoamericano equilibrado.

\section{CONCLUSIONES}

Del análisis precedente es posible apreciar que el presidencialismo latinoamericano se constituye como una categoría autónoma dentro de las formas de gobierno democráticas, tal como lo ha destacado la doctrina comparada. Por

12 STC Rol nro. 458-2005, voto de minoría 7.․ 
su parte, destaca el hecho que dentro de este es posible distinguir distintas tipologías, las que están determinadas por el grado de intensidad en los contrapesos institucionales al Primer Mandatario, principalmente, con ocasión de la función legislativa.

La Constitución chilena contempla una clara asimetría entre el Presidente de la República y el Congreso Nacional, la cual no solo da cuenta de una diferencia con el régimen de gobierno norteamericano, sino que también de sus rasgos compartidos con las formas de gobierno existentes en la región. En tal sentido, es posible catalogar esta relación de poderes a la luz de las categorías del presidencialismo latinoamericano, quedando pendiente precisar a cuál de ellas se acerca más, esto es, a formas más equilibradas, o bien a aquellas menos deferentes con los demás poderes públicos.

Al respecto, se argumenta la necesidad de incorporar a este análisis la interacción del Presidente, en cuanto principal órgano colegislador, con el Tribunal Constitucional, por cuanto este no solo forma parte de la función legislativa, sino que también, participa intensamente en el proceso de formación de la ley, a través del control preventivo obligatorio de las leyes orgánicas constitucionales.

De esta manera, desde el punto de vista normativo, a primera vista, se aprecia un marcado desequilibrio entre los poderes públicos Presidente de la República-Congreso Nacional, descripción sostenida por la mayoría de la doctrina nacional. Sin embargo, una mirada dinámica del texto constitucional permite relativizar esta posición, atendida la existencia de contrapesos institucionales, como las LOC y su control preventivo obligatorio por el TC, que desde el punto de vista práctico han tenido un rol relevante en la morigeración de la forma de gobierno.

En efecto, desde el punto de vista de la práctica jurisprudencial, la forma de gobierno en el Chile actual se configura como un presidencialismo latinoamericano equilibrado. En primer lugar, por el carácter expansivo de las LOC, las cuales permiten al TC controlar con mayor intensidad los proyectos de ley. Y, en segundo lugar, por el carácter poco deferente de algunas sentencias del Tribunal Constitucional respecto de prerrogativas propias del Primer Mandatario, como consta en la práctica de las decisiones atípicas.

En síntesis, es posible concluir que indistintamente las categorías que utilicemos, la forma de gobierno que opera en la Constitución actual se articula, en definitiva, como un presidencialismo latinoamericano equilibrado, morigerado por el contrapeso real que realiza el Tribunal Constitucional en el proceso de formación de las leyes, particularmente, cuando se realiza el control preventivo obligatorio de las leyes orgánicas constitucionales. 


\section{REFERENCIAS}

Ackerman, Bruce (2007), La nueva división de poderes, México DF, Fondo de Cultura Económica.

Bazán, Víctor (2015), «La justicia constitucional en América Latina y algunos desafíos que afronta», Rivista telemática giuridica dell'Associazzione Italiana dei Costituzionalisti, nro. 1, pp.1-27.

Boeninger, Edgardo (2008), «Relaciones entre partidos, Gobierno y Parlamento en el Sistema presidencial chileno», en Fontaine, Arturo et al. (Editores), Reforma de los partidos politicos en Chile, Santiago, PNUD, CEP, Libertad y Desarrollo, Proyectamérica y CIEPLAN, pp. 191-219.

Bon, Pierre (1998), «Francia», en Aja, Eliseo (editor), Las tensiones entre el Tribunal Constitucional y el legislador en la Europa actual, Barcelona, Ariel.

Bordalí, Andrés (2005), «Análisis crítico del control preventivo y represivo de constitucionalidad de las normas jurídicas por los Tribunales Constitucionales», en Nogueira, Humberto (coordinador), Jurisdicción Constitucional en Chile y América Latina: presente y prospectiva, Santiago, Lexis-Nexis.

Cappelletti, Mauro (1966), El control judicial de la constitucionalidad de las leyes en el Derecho Comparado, México DF, UNAM.

Cappelletti, Mauro (1980), «El "formidable problema" del control judicial y la contribución al análisis comparado», Revista de Estudios Políticos, nro. 13, pp. 61-103.

Carpizo, Jorge (2007), Concepto de democracia y sistema de gobierno en América Latina, México DF, UNAM.

Cordero, Eduardo (2005), «La facultad fiscalizadora de la Cámara de Diputados», en Zúñiga, Francisco (coordinador), Reforma Constitucional, Santiago, Lexis-Nexis.

Cruz-Coke, Carlos (2009), Instituciones Políticas y Derecho Constitucional, Santiago, Universidad Finis Terrae.

Díaz Revorio, Francisco (2001), Las sentencias interpretativas del Tribunal Constitucional, Valladolid, Editorial Lex Nova.

Fermandois, Arturo y García, José Francisco (2009), «Origen del presidencialismo chileno: reforma constitucional de 1970, ideas matrices e iniciativa legislativa exclusiva», Revista Chilena de Derecho, vol. 36, nro. 2, pp. 281-311. 
García Belaunde, Domingo (2004), «Los tribunales constitucionales en América Latina», Revista de Derecho Político, nro. 61, 309-321.

Gargarella, Roberto (2015), La sala de máquinas de la Constitución. Dos siglos de constitucionalismo en América Latina (1810-2010), Madrid, Katz.

Godoy, Óscar (2003), «Parlamento, presidencialismo y democracia protegida», Revista de Ciencia Política, vol. 23, nro. 2, pp. 7-42.

Gómez, Gastón (2005), «El nuevo Tribunal Constitucional chileno», en Zúñiga, Francisco (coordinador), Reforma Constitucional, Santiago, Lexis-Nexis, pp. 651-684.

Guastini, Ricardo (2017), Interpretar y argumentar, Madrid, 1. ${ }^{a}$ reimpresión, Centro de Estudios Políticos y Constitucionales.

Huneeus, Carlos (2012), «El presidencialismo semisoberano», Revista Uruguaya de Ciencia Política, vol. 21, pp.31-54.

Kelsen, Hans (1999), ¿Quién debe ser el defensor de la Constitución?, Madrid, 2.a ed., Tecnos.

Landa, César (2017), «Constitucionalismo Latinoamericano», Revista Direito UFMS, vol. 3, nro. 1, pp. 7-21.

Loewenstein, Karl (1949), «La "Presidencia" fuera de los Estados Unidos (Estudio comparativo de instituciones políticas)», Boletín del Institu to Derecho Comparado de México, nro. 5, pp. 15-64.

Meléndez, Felipe (2017), «La influencia del control preventivo en el diseño del régimen presidencial chileno», Anuario Iberoamericano de Justicia Constitucional, nro. 21, pp. 81-110.

Mohor, Salvador y Varas, Paulino (1986), «En torno a la Ley Orgánica Constitucional sobre sistema de inscripciones electorales y servicio electoral», Revista de Derecho, nro. 10, pp. 253-288.

Molina, Hernán (1997), «El presidencialismo en la Constitución de 1980. Posibilidad de un presidencialismo racionalizado», Revista de Derecho, nro. 202, 93-103.

Molina, Hernán (2006), Manual de Derecho constitucional, 6. ${ }^{\text {a }}$ edición, Santiago, LexisNexis.

Navarro, Enrique (2014), «Reformas a la Constitución chilena», Revista de Derecho Público, edición especial, pp. 13-23 
Nogueira, Humberto (2004), «Consideraciones sobre las sentencias de los Tribunales Constitucionales y sus efectos en América del Sur», Ius et Praxis, vol. 10, nro. 1; pp. 113-158.

Nogueira, Humberto (2008), «Informe a la Comisión Especial de Modernización del Régimen Político chileno sobre el perfeccionamiento del sistema constitucional, con especial énfasis en el tipo de gobierno», Estudios Constitucionales, Año 6, nro. 2, pp. 503-525.

Nogueira, Humberto (2015). «Los presidencialismos latinoamericanos», en Carbonell, Miguel, Fix-Fierro, Héctor y Valadés, Diego (coordinadores), Estado constitucional, derechos humanos, justicia y vida universitaria. Estudios en homenaje a Jorge Carpizo. Estado constitucional, IV, 2, México DF, UNAM, pp. 403-441.

Nohlen, Dieter (2011), «El presidencialismo: Análisis y diseños institucionales en su contexto», Revista de Derecho Público, núm. 74, pp. 87-111.

Nolte, Detlef (2003), «El Congreso chileno y su aporte a la consolidación democrática en perspectiva comparada», Revista de Ciencias Política, vol. XXIII, nro. 2, pp. 43-67.

Orozco, José y Zovatto, Daniel (2009), «Alcance de los poderes presidenciales en los países latinoamericanos», en Orozco, José, Ellis, Andrew y Zovatto, Daniel (Coordinadores), Cómo hacer que funcione el sistema presidencial, México DF, UNAM, pp. 45-97.

Pardo, Javier (1990), El Consejo Constitucional francés. La jurisdicción constitucional en la Quinta República, Madrid, Centro de Estudios Políticos y Constitucionales.

Pasquino, Gianfranco (2011), Nuevo curso de Ciencia Política, México DF, Fondo de Cultura Económica.

Ríos, Lautaro (2013), «El presidencialismo en la República de Chile», Revista de Derecho Público, nro. 79, pp. 145-175.

Ruiz-Tagle, Pablo (2006), «La trampa del neopresidencialismo: la Constitución "Gatopardo"», en Cristi, Renato y Ruiz-Tagle, Pablo, La República en Chile. Teoría y práctica del constitucionalismo republicano, Santiago, LOM, pp. 197-223.

Ruiz-Tagle, Pablo (2014), «Democracia y constitucionalismo ejecutivo en Latinoamérica y Chile», en Cristi, Renato y Ruiz-Tagle, Pablo, El constitucionalismo del miedo, Santiago, LOM, pp. 153-161.

Ruiz-Tagle, Pablo (2016), Cinco repúblicas y una tradición. Constitucionalismo chileno comparado, Santiago, LOM. 
Sentencia del Tribunal Constitucional de Chile, Rol nro. 299, del año 1999.

Sentencia del Tribunal Constitucional de Chile, Rol nro. 356, del año 2002.

Sentencia del Tribunal Constitucional de Chile, Rol nro. 458, del año 2005.

Sentencia del Tribunal Constitucional de Chile, Rol nro. 1024, del año 2008.

Sierra, Lucas (2011), «La supramayoría en la potestad legislativa chilena como anomalía democrática», en Sierra, Lucas y Mac-Clure, Lucas, Frente a la mayoría: leyes supramayoritarias y Tribunal Constitucional en Chile, Santiago, Centro de Estudios Públicos, Corporación de Estudios para Latinoamérica, Libertad y Desarrollo, Proyecta América, pp. 13-168.

Soto, Sebastián (2017), «Costumbres y prácticas legislativas en el Derecho Constitucional», en Obando, Iván (compilador), Estudios constitucionales y parlamentarios en homenaje al profesor Jorge Tapia Valdés, Santiago, Ril Editores, 127-152.

Tsebelis, George (2006), Jugadores con veto. Cómo funcionan las instituciones, México DF, Fondo de Cultura Económica.

Valadés, Diego (2014), «Formación y transformación del sistema presidencial en América Latina. Una reflexión sobre el ius constitutionale commune latinoamericano», en Fix-Fierro, Héctor, Bogdandy, Armin von y Morales, Mariela (coordinadores), Ius constitutionale commune en América Latina. Rasgos, potencialidades y desafíos, México DF, UNAM, pp. 169-197.

Valenzuela, Arturo (1985), «Orígenes y características del sistema de partidos en Chile: proposición para un gobierno parlamentario», Estudios Públicos, nro. 18, pp. 1-69.

Verdugo, Mario; Pfeffer, Emilio, y Nogueira, Humberto (1999), Derecho Constitucional, Tomo II, Santiago, 2. ${ }^{a}$ edición, Editorial Jurídica de Chile.

Zapata, Patricio (2006), «Las sentencias atípicas en la jurisprudencia del Tribunal Constitucional chileno (TCCH)», Estudios Constitucionales, año 4, nro. 2, pp. 175-197.

Zapata, Patricio (2016), Justicia Constitucional. Teoría y práctica en el Derecho chileno y comparado, Santiago, 1. ${ }^{a}$ reimpresión, Editorial Jurídica de Chile. 